\title{
Educação superior em tempos de retrocessos e os impactos na formação profissional do Serviço Social
}

\section{Higher education in times of setbacks and the impacts on Social Service professional training}

\author{
Eblin Farage ${ }^{a}$ \\ (1) https://orcid.org/0000-0002-6307-8062
}

Resumo: $O$ presente artigo aborda o ensino remoto emergencial (ERE) no contexto das contrarreformas do Estado e da crise estrutural do capitalismo, a partir das imposições do modelo de educação terciária desenhada pelos organismos internacionais do capital. Explicita elementos da contrarreforma administrativa e do processo de reestruturação do mundo do trabalho, analisando-os de forma articulada à conjuntura e sinalizando alguns dos impactos para a formação profissional do Serviço Social.

Palavras-chave: Ensino remoto emergencial. Contrarreformas. Formação profissional.
Abstract: This article addresses emergency remote education (ERE) in the context of state counter-reforms and the structural crisis of capitalism, based on the impositions of the tertiary education model designed by international capital organizations. It explains elements of the administrative counter-reform and the process of restructuring the world of work by analyzing in an articulated manner and pointing out some of the impacts on the professional training of Social Work.

Keywords: Emergency remote education, Counter-reforms, Professional training. 


\section{Introdução}

\section{1 quadra histórica que vivemos impõe retrocessos estruturantes aos direitos sociais e às políticas públicas no Brasil, agregando-se, face à ascensão da extrema direita, uma perspectiva fundamentalista, miliciana e militarizada que incide de forma voraz na educação superior pública. Nesse sentido, no governo Bolsonaro a política ultraneoliberal se encontra com a anticiência, produzindo um aparato ideológico alienante que marca a conjuntura.}

Segundo Konder (2009, p. 191), "de um modo ou de outro, o status de alienação em que vivemos atinge todas as formas de consciência vigentes entre nós", forjando uma cultura que se espraia entre a população, contagiando segmentos da classe trabalhadora. É nesse contexto que a educação pública superior brasileira vem sendo duramente golpeada por meio de um processo intensificado de mercantilização, desestruturação, privatização e perda de autonomia, que, entre outras coisas, tem se expressado nos sucessivos cortes orçamentários que somam, desde 2015, mais de 6 bilhões de reais.

A política alienante do capital quer impor uma nova cultura, naturalizando um "novo normal" que não encontra sentido nem mais na qualificação da força de trabalho. Afinal, em um mercado de trabalho cada vez mais desestruturado, com cerca de 27 milhões $^{1}$ de pessoas, que, segundo o IBGE, não estão trabalhando nem procuraram emprego no último período, com crescente número de desempregados e subempregados, com mais de $50 \%$ da força de trabalho inserida no mercado informal, "uberizados", terceirizados ou lançados à própria sorte no mercado do empreendedorismo liberal, parece não ter sentido investir em formação. Assim, o trabalho, como afirma Antunes (2018), se torna um privilégio da servidão e se encontra com o apoliticismo, que, segundo Konder

\footnotetext{
Disponível em: https://g1.globo.com/economia/noticia/2020/09/04/desemprego-diante-da-pandemia-volta-a-crescer-na-segunda-semana-de-agosto-aponta-ibge.ghtml. Acesso em: 17 out. 2020.
} 
(2009, p. 186), tem o sentido de "impedir que as classes e camadas da população excluídas do exercício do poder tomem consciência das suas potencialidades políticas e queiram participar do controle da vida social".

Nesse contexto, um conjunto de contrarreformas, que retiram direitos dos trabalhadores, avança, como as da previdência, a trabalhista e a $\mathrm{EC} / 95$, a suspensão dos concursos públicos por intermédio da lei complementar no 173/2020 e a proposta de EC no 32/2020, da contrarreforma administrativa. Mudanças legislativas constitucionais e infraconstitucionais que devem ter seus impactos analisados na conjuntura de ascensão da extrema direita e do recrudescimento do conservadorismo.

Nesse caminho, o presente artigo, dividido em duas partes, além dessa breve introdução e de uma sintética conclusão, versará sobre os elementos atuais da contrarreforma da educação em curso e suas bases de sustentação históricas, bem como sobre os impactos para a formação profissional do Serviço Social.

\section{Educação superior e as contrarreformas}

A conjuntura atual deve ser por nós analisada à luz de duas contrarreformas em curso no Brasil: a do ensino superior público, que se agrava com a imposição do ensino remoto emergencial como a única alternativa no período de isolamento social, e a contrarreforma administrativa, enviada pelo Executivo ao Congresso Nacional em setembro de 2020.

A primeira, a contrarreforma da educação, deve ser analisada de maneira articulada com outras ações que, antes mesmo da pandemia do novo coronavírus, já impactavam a educação superior pública, como: a elevação do percentual de ensino a distância nos cursos presenciais que passou de 20\% para 40\%, prevista na Portaria no 2117/2019 do MEC; a Emenda Constitucional no 95, de 2016, que congelou os investimentos em políticas públicas até o final de 2021; a terceirização das atividades fins, aprovada pela Lei no 13.429/2017; os sucessivos cortes de verbas para a educação superior pública, entre eles o já anunciado corte de $8,7 \%$ nos 
gastos discricionários para 2021 previsto no Projeto de Lei Orçamentária enviado pelo Executivo ao Congresso Nacional em setembro de 2020.

Além desses elementos, que impactam diretamente a educação pública superior, ainda temos que considerar as contrarreformas da Previdência, que implicaram grande retirada de direitos para o conjunto dos servidores públicos, entre os quais os profissionais da educação. E, em um horizonte próximo, há a contrarreforma administrativa, PEC n 32/2020, que, se aprovada, significará uma verdadeira desestruturação do conjunto dos serviços públicos conquistados na luta da classe trabalhadora ao longo dos últimos trinta anos, desde a Constituição Federal de 1988.

Ao conjunto de contrarreformas, que tem por base o projeto do capital em sua versão neoliberal, a partir da década de 1990, no Brasil, se agregam as transformações do mundo do trabalho e as regressões de direitos trabalhistas que, ao alterarem as formas de contratação com a desestruturação da Consolidação das Leis Trabalhistas (CLT), impactam nas condições de vida. Contrarreformas e transformações que intensificam o processo de precarização das relações de trabalho, ampliando a terceirização, o subemprego e a exploração dos trabalhadores. Assim, como afirma Antunes (2018), o período da indústria 4.0 inaugura a fase do "privilégio da servidão" que, combinando o arcaico e o moderno, nos termos de Ianni (2004), impulsiona o período da "uberização" do trabalho no mundo das plataformas digitais do capital.

Essas transformações, no contexto da chamada crise internacional e estrutural do capital e da chamada crise do socialismo real, incidem nas relações sociais, impactando os direitos sociais, entre os quais a educação pública. A primeira crise, entre outras coisas, se evidencia no aprofundamento da desigualdade social, com a ampliação do fosso entre ricos e pobres e a elevação da pauperização de amplos segmentos da classe trabalhadora. Já a segunda crise, a do chamado socialismo real, se evidencia no nível de fragmentação da organização dos trabalhadores e na limitação do horizonte de luta de parte das entidades representativas da classe trabalhadora, ao possível dentro da ordem do capital. 
O capitalismo entra em crises cíclicas, o que, a partir da década de 1970, passou a ser considerado uma crise estrutural, pela sua incapacidade de superar as contradições mais evidentes e retomar as taxas de lucros, necessitando de novas formas de apropriação privada da riqueza socialmente produzida. Reestruturado por um conjunto de mudanças, o capitalismo passa a ter novas demandas para a organização do Estado, entendido, nos termos de Marx (2001), como um aparelho privado de hegemonia da burguesia que serve para garantir o desenvolvimento do sistema capitalista. Assim, baseada no Consenso de Washington de 1989, uma nova orientação norteia a reorganização do Estado, a partir dos preceitos neoliberais, implicando: i) parcerias público-privadas (PPP), ii) minimização da responsabilidade do Estado com políticas públicas e sociais; iii) mercadorização dos direitos sociais; e iv) criminalização dos que lutam e repressão.

Esses elementos se articulam ainda, no período recente, a um processo de recrudescimento do conservadorismo, que impulsiona e ao mesmo tempo é impulsionado pela ascensão da extrema direita em vários países do mundo, como aconteceu no Brasil com a eleição de Jair Bolsonaro em 2018. Essa realidade, articulada e combinada, como explicitado na teoria do desenvolvimento desigual e combinado do capitalismo, gera um caldo cultural de regressão civilizatória, que, entre outras coisas, impõe a retirada de direitos, fomenta uma polarização social entre projetos antagônicos de sociedade e legitima ideologicamente o discurso de prioridade do capital, qual seja, a manutenção do lucro, ainda que ao custo da vida dos trabalhadores.

Essa talvez seja a nova versão da onda conservadora do capital que a pandemia da covid-19 explicitou no Brasil e em diversas partes do mundo. Para vários governos, entre os quais o brasileiro, a pandemia foi caracterizada como "uma gripezinha", como enunciado pelo presidente da República, para, assim, impulsionar a reabertura do comércio. A mesma estratégia foi implantada por inúmeros governos municipais e estaduais, evidenciando que os lucros estão acima da vida. 
Assim, aliando-se as contrarreformas à perspectiva anticiência, fundamentalista, miliciana e militarizada, impulsiona-se uma verdadeira onda regressiva que impõe um retrocesso civilizatório pautado na perseguição, em fake news e no autoritarismo, que recuperam elementos da particularidade social brasileira, como o colonialismo, a escravização, a europeização cultural, o machismo, o sexismo e as opressões, de diferentes tipos. Nesse contexto, toda a sociabilidade é repensada, inclusive a educação superior.

É assim, em meio ao agravamento da conjuntura, que o governo federal, aproveitando-se da pandemia, que limita os atos e movimentos de rua e, portanto, a possibilidade de resistência da comunidade acadêmica e que defende o isolamento social, lança mão do ensino remoto emergencial, como uma estratégia para buscar a "naturalização" da educação mediada pela tecnologia. Essa estratégia não pode ser considerada nova, mas certamente é ainda mais rebaixada do que a proposta da educação terciária do Banco Mundial e demais organismos internacionais, como Fundo Monetário Internacional (FMI), Banco Mundial (BM), Organização Mundial do Comércio (OMC) e Unesco.

Esse processo que impõe uma contrarreforma da educação, que tem na mediação da tecnologia uma forma de acesso ao ensino superior, tem marco importante no denominado processo de Bolonha que tem como referência central a Declaração de Bolonha de 1999. A declaração, assinada inicialmente por 27 países, teve o objetivo de organizar um sistema educacional para os países da Comunidade Europeia para torná-lo mais competitivo no mundo. A partir daí, em reuniões bianuais da comunidade europeia para pensar a educação, foi se avançando em um modelo que acabou por contagiar também países da América Latina, em uma explicitação da dimensão colonizadora, com a subordinação de países de capitalismo tardio aos países de capitalismo desenvolvido. Assim, "os sujeitos políticos coletivos do capital”, como denominado por Lima (2007), passam a adaptar os preceitos pensados para a Europa à realidade dos países da América Latina. 
Essa influência marca os diferentes governos brasileiros no período pós-CF/88 que, com intensidades e formas diferentes, seguiram os caminhos do projeto mercantilizador da educação, baseando-se: i) no repasse de verba pública para a expansão do ensino superior privado; ii) na privatização interna das instituições públicas de ensino; iii) na intensificação da venda de serviços por parte das instituições de ensino públicas; iv) no incentivo às parcerias público-privadas; v) na criação das fundações de direito privado no interior das instituições de ensino públicas; vi) na redução dos currículos da graduação, a partir das exigências do Ministério da Educação; vii) na redução do tempo destinado à formação no nível de pós-graduação nas instituições de ensino; viii) na terceirização no interior das instituições públicas de ensino; ix) na privatização interna das instituições; $x$ ) na expansão precarizada da educação superior pública, como forma de atender às exigências dos organismos internacionais de certificação de larga escala, sem preocupação com a qualidade; e xi) na certificação em larga escala, tendo na redução dos currículos e no ensino a distância suas estratégias centrais.

As consequências imediatas para as instituições de ensino superior públicas são: i) a fragilização do tripé ensino-pesquisa-extensão conquistado no artigo 207 da CF/88; ii) a intensificação do trabalho docente; iii) a precarização das condições de trabalho; iv) a desestruturação da carreira docente; v) a competição entre os docentes; vi) a seletividade dos programas de pós-graduação, com a política constante de redução de recursos e das bolsas de estudo; e vii) o adoecimento docente.

Como afirma Antunes (2020, p. 25), “essa complexa engrenagem sociometabólica tornou a corrosão do trabalho um imperativo ainda maior no nosso tempo". Se, como afirma o autor, o trabalho não pode ser eliminado, por ser a única mercadoria capaz de gerar mais valor, as condições de trabalho serão devastadas, intensificando uma realidade laboral em que as tecnologias de comunicação e informação se tornam "plasmadas, impulsionadas e comandadas pelas relações capitalistas em sua forma mais destrutiva” (p. 11). Essa conformação atingirá o conjunto 
do funcionalismo público e também a educação superior, com implicações diretas na formação profissional.

\section{0 ensino remoto emergencial e a formação profissional do Serviço Social}

O ensino remoto emergencial deve ser compreendido como um dos elementos do processo de contrarreforma da educação em curso no Brasil e em toda a América Latina. Não só porque impulsiona um novo modelo de educação, que nem pode ser considerado educação a distância, como regulamentada no Decreto no 9.057, de 25 de maio de 2017, mas também porque é fruto de uma modalidade de trabalho docente adequado ao processo de reestruturação produtiva e precarização do mundo do trabalho que esvazia o sentido do fazer profissional dos professores universitários.

Como afirma Antunes (2020, p. 19):

Não faltam evidências, então, sobre a direção que o capital e seus gestores vêm indicando, inclusive nos setores em que o trabalho digital, on-line, se desenvolve. Algumas práticas se convertem em verdadeiros laboratórios de experimentação, de que são exemplos o home office, o teletrabalho e, no universo educacional, o EAD (Ensino a Distância).

E é justamente esse "laboratório de experimentação", que está se tornando o ERE, que deve ser questionado por todos que consideram a educação pública um patrimônio conquistado pela classe trabalhadora e defendem que seja gratuita, laica, de qualidade, antipatriarcal, antissexista, anticapacitista, anti-LGBTfóbica e universal. Por isso, é essencial analisar os elementos do ERE e as ameaças postas na contrarreforma administrativa para o ensino superior público e seus impactos na formação profissional do Serviço Social.

$\mathrm{Na}$ maior parte das instituições de ensino superior (IES), o período denominado como excepcional foi implantado com pouco ou nenhum 
diálogo com a comunidade acadêmica. A maior parte das IES aderiu ao isolamento social e suspendeu as atividades presenciais na semana de 16 de março de 2020. Em alguns casos, como a Universidade Federal de Santa Maria (UFSM), a Universidade Federal do Mato Grosso do Sul (UFMS) e a Universidade Estadual do Mato Grosso do Sul (UEMS), entre outras, impôs-se uma transposição da grade presencial para a modalidade remota na mesma semana em que as atividades presenciais foram suspensas. No dia 18 de março de 2020, o MEC, ${ }^{2}$ através de uma resolução, autorizou o ensino mediado por tecnologias, deixando sob a responsabilidade de cada instituição a definição do processo. Posteriormente, em 16 de junho, com a Portaria n. 544, regulamentou a substituição do ensino presencial pelo remoto.

Nesses casos, a adesão ao ERE, independentemente do nome que tenha recebido em cada IES, se deu de forma autoritária, desrespeitando as instâncias democráticas da instituição, como os conselhos superiores, sem nenhum diálogo com as entidades representativas, como sindicato docente, de técnico-administrativos e diretório central dos estudantes, bem como sem debate com os docentes via departamentos e colegiados de cursos. A imposição por parte dos gestores sequer considerou questões materiais, como a possibilidade de acesso e condição de manejo das tecnologias por parte de docentes e discentes, assim como o MEC, que inicialmente não demonstrou nenhuma preocupação sobre as condições de trabalho remoto, de acesso à tecnologia por docentes e discentes e nem sobre as condições de saúde.

Outro conjunto de instituições tentou forjar um processo aparentemente democrático, criando um processo de submissão à comunidade acadêmica das propostas de resoluções para a regulamentação do ERE. Não houve, porém, efetivo debate, uma vez que na maior parte dessas instituições a aprovação das propostas aconteceu de forma aligeirada,

2 Disponível em: http://portal.mec.gov.br/busca-geral/12-noticias/acoes-programas-e-projetos-637152388/86441-mec-autoriza-ensino-a-distancia-em-cursos-presenciais. Acesso em:17 out. 2020. 
sem tempo hábil para o debate, o estudo e a maturação necessária para o planejamento desse período absolutamente excepcional. Nessas instituições, alguns elementos marcaram o processo: i) ausência ou baixa qualidade de diagnósticos sobre a realidade material, objetiva e subjetiva de docentes e discentes; ii) redução dos mapeamentos realizados ao aspecto do acesso à tecnologia; iii) ausência de transparência sobre os resultados dos levantamentos realizados; iv) desvinculação do tripé ensino-pesquisa-extensão; v) subordinação às tecnologias dos grandes conglomerados tecnológicos que dominam as plataformas de mediação tecnológica; vi) esvaziamento do processo de ensino-aprendizagem com a

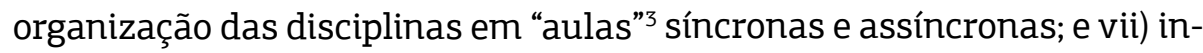
viabilização do estágio como parte constitutiva da formação profissional.

Nesse cenário, portanto, foi desconsiderada a realidade material e de profunda desigualdade de acesso à tecnologia. Segundo a pesquisa TIC Domicílios de $2018,{ }^{4}$ o país tem cerca de 4,5 milhões de brasileiros sem acesso à internet banda larga; a maior parte das famílias pobres, das classes D e E, cerca de $85 \%$, quando acessam a internet, o fazem do celular; e mais de $50 \%$ dos domicílios da área rural não possuem acesso à internet. Além disso, 38\% das casas não possuem acesso à internet; $58 \%$ das casas não têm computador no Brasil e 59\% das pessoas das chamadas classes D e E não navegam na internet, ou seja, o arremedo de ensino a distância acaba por contribuir para um processo de nova elitização do ensino superior, excluindo, novamente, os segmentos mais pauperizados da população das instituições públicas de ensino.

A educação a distância, considerada como uma modalidade educacional, prevê que:

A mediação didático-pedagógica nos processos de ensino e aprendizagem ocorra com a utilização de meios e tecnologias de informação e

\footnotetext{
3 A palavra "aulas" está aspeada pela compreensão de que as atividades remotas que estão realizadas no período do ERE não devem ser classificadas como aulas, dado o esvaziamento do sentido do processo de ensino-aprendizagem que norteia os processos educativos.

4 Disponível em: https://data.cetic.br/cetic/explore?idPesquisa=TIC_DOM. Acesso em: 10 out. 2020.
} 
comunicação, com pessoal qualificado, com políticas de acesso, com acompanhamento e avaliação compatíveis, entre outros, e desenvolva atividades educativas por estudantes e profissionais da educação que estejam em lugares e tempos diversos (Brasil, 2017, artigo 1º do Decreto no 9.057 de 2017).

Essa explicitação do decreto de 2017, que altera a Lei de Diretrizes e Bases da Educação de 1996, nos desautoriza a caracterizar o atual ensino remoto de educação a distância. Então, o que estamos fazendo? Se não é educação e se não podemos chamar de aula gravações de vídeo, power point, palestras em plataformas virtuais sem interação, sem olho no olho, sem expressões de dúvida e questionamentos, o que estamos fazendo? O esvaziamento do sentido didático-pedagógico do processo de ensino-aprendizagem deve ser questionado. Atividades remotas síncronas que sequer garantem a presença dos discentes do outro lado da tela do computador ou do celular, que não envolvem avaliação (como algumas resoluções determinam), que não têm cobrança de presença, que não têm interação, que não têm participação efetiva, dada as limitações tecnológicas, não devem ser caracterizadas como aulas. Temos ainda que considerar a restrição de acesso bibliográfico disponível na internet, o que representa uma fragilização dos conteúdos e da estrutura curricular.

A realidade de acesso tecnológico deve ser compreendida no contexto de profunda transformação do mundo do trabalho que, agravado pela realidade da pandemia, faz a população brasileira amargar cerca de 12,9 milhões de desempregados, ${ }^{5}$ segundo dados do Instituto Brasileiro de Geografia e Estatística (IBGE) de agosto de 2020, além de 29 milhões de trabalhadores informais. Em treze semanas, segundo matéria do G1, o número de desempregos aumentou em 31,2\%.

Assim, a desigualdade produzida pelas relações de produção se aprofunda, e, para uma sociedade cada vez mais desigual, o processo de apassivamento de diferentes segmentos da classe trabalhadora se torna

5 Disponível em: https://g1.globo.com/economia/noticia/2020/09/04/desemprego-diante-da-pandemia-volta-a-crescer-na-segunda-semana-de-agosto-aponta-ibge.ghtml. Acesso em: 17 out. 2020. 
fundamental. Naturaliza-se a desigualdade e cria-se a perspectiva de sua superação, não pela reorganização do sistema produtivo, mas pelo impulso das competências individuais. A nova reconfiguração do mundo do trabalho, baseada nas inovações tecnológicas, abre o mundo para um período de trabalho digital, virtual, teletrabalho, ampliando o processo do "patrão de si mesmo", de expansão do mundo dos autônomos, do processo de "pjotização", ${ }^{6}$ de "uberização", de horistas através do trabalho intermitente, criando-se, nos termos de Antunes (2018), o escravo digital, que atinge também a educação superior.

A pandemia do novo coronavírus acelerou o processo de digitalização e virtualização do mundo do trabalho no setor público, constituindo-se hoje como uma forma de "economia" para o governo, na medida em que os custos do trabalho remoto estão recaindo sobre os trabalhadores, sem qualquer tipo de auxílio por parte do Estado; constitui-se também como uma nova forma de apropriação privada do fundo público, já que o Estado não se preocupou em criar plataformas públicas e livres nem mesmo em estatizar empresas de telecomunicação que hoje gerenciam, junto com os grandes conglomerados tecnológicos, todo o serviço de mediação para o trabalho e o ensino remoto.

Na lógica do trabalho remoto, agora também direcionado ao ensino, um chamado "novo normal" vai se instituindo em uma perspectiva de esvaziamento do trabalho do professor, impondo um fim nos limites entre o espaço público e o privado, uma vez que as casas se tornam as "salas de aula", intensificando o trabalho por meio de longos períodos de acesso aos meios tecnológicos que acabam por gerar e/ou intensificar o adoecimento docente.

Vale destacar que a intensificação do trabalho se dá em um contexto de absoluta excepcionalidade, em que a maior parte dos docentes e

\footnotetext{
6 Trabalhadores que abrem suas próprias "firmas", através de processos simplificados criados pelo governo, em que é possível trabalhar de forma autônoma e emitir nota fiscal de serviço. Nessa modalidade, os trabalhadores não dispõem de direitos trabalhistas, uma vez que são considerados "patrões de si mesmos".
} 
discentes teve que reorganizar a vida e responder a demandas do trabalho doméstico, do cuidado com crianças, pessoas com deficiência e idosos, além dos efeitos subjetivos, adoecedores, gerados pelo distanciamento social, em especial de entes queridos.

Outro elemento importante, que expressa a perversidade desse modelo de ensino, é o alto grau de exposição dos docentes com aulas gravadas e disponibilizadas em plataformas digitais ou mesmo a possibilidade de gravação sem autorização, que pode, em tempo de projetos de escola sem partido, de perseguição docente e de tentativa de criminalização do pensamento crítico, ter consequências graves.

Na mesma linha da desestruturação dos direitos e da educação pública superior, é necessário considerar a PEC no 32/2020, proposta de reforma administrativa que prevê uma verdadeira desestruturação do sistema público de garantia de direitos.

A contrarreforma, pautada nos preceitos da reorganização do Estado para atender às necessidades do capitalismo em crise, ataca frontalmente os direitos conquistados na $\mathrm{CF} / 88$. Para o Serviço Social, a CF/88 traz conquistas fundamentais para a mediação de direitos junto à população mais pobre, superando a lógica de políticas de governo e negando a lógica do apadrinhamento e do favor, historicamente arraigados na estrutura social brasileira.

Assim, é necessário registrar que os eixos centrais dessa contrarreforma incidem diretamente na formação profissional e na ação profissional dos assistentes sociais. Uma reforma que, entre outras coisas: i) equipara a lógica de gerenciamento do setor público ao setor privado, sem manter direitos previstos na CLT e retirando direitos do funcionalismo; ii) será regulamentada por lei complementar em vários dos pontos anunciados na PEC no 32/2020, o que sinaliza um perigo, pois pode aprofundar a retirada de direitos, inclusive para os atuais servidores públicos, uma vez que a tramitação de lei complementar é muito mais simplificada e aligeirada no Congresso Nacional; iii) afeta a estabilidade do conjunto dos servidores públicos das três esferas, com exceção dos 
“cargos típicos de Estado”; iv) retira direitos conquistados como: licença-prêmio, anuênios e outros; v) possibilita a contratação de militares da ativa para funções públicas na saúde e no magistério; vi) impõe um caráter autoritário, prevendo poderes ao presidente da República, por meio de decreto, de alterações estruturais nos serviços públicos. Ao reestruturar as políticas públicas, terá incidência na formação profissional dos futuros assistentes sociais.

Nesse contexto, somos convocados a pensar os impactos do ERE, assim como as ameaças da contrarreforma administrativa para a formação profissional do Serviço Social. Primeiro, vale registrar que mais de uma dezena de cursos de Serviço Social de instituições públicas de ensino se posicionou contra a imposição do ERE. Entre eles, merecem destaque os que lançaram notas públicas, como as Escolas da UFF/Niterói, UFES, UFS, UFBA, Ufam/Parintins, Ufal, UFPE, UFPB, UNB, entre outras, que explicitaram o descontentamento com a forma e o conteúdo do "novo normal”. Certamente, o posicionamento do Serviço Social, expresso também pela Associação Brasileira de Ensino e Pesquisa em Serviço Social (Abepss) e pelo Conselho Federal de Serviço Social (CFESS), é parte do acúmulo histórico da categoria que há décadas discute, reflete e produz sobre o EaD e seus impactos na formação profissional.

Assim, partindo do acúmulo, da realidade e tendo como base o projeto ético-político do Serviço Social, a lei que regulamenta a profissão, o código de ética profissional e o currículo do Serviço Social, pode-se afirmar a impossibilidade de transposição do ensino presencial para o ensino remoto. Defender a não transposição do ensino não significa defender que não seja realizada nenhuma atividade remota com os discentes. Ao contrário, o contato com os estudantes, em especial nesse momento da pandemia, é de fundamental importância. Mas a relevância do contato consiste na possibilidade de identificar como os estudantes estão e o que a universidade pode fazer por eles nesse momento de pandemia.

A transposição do ensino presencial para o remoto, no caso do Serviço Social, pode fragilizar o próprio projeto ético-político, que não pode 
prescindir, entre outras coisas, de uma formação profissional consistente com sólido arcabouço teórico, de ter o estágio como um período privilegiado da formação profissional, bem como de um espaço formativo em que docentes e discentes tenham liberdade de expressão, livre escolha dos conteúdos e dos métodos pedagógicos a partir do currículo.

Outro elemento importante a ser considerado são os dados sobre o perfil dos estudantes de Serviço Social que a ABEPSS explicitou em sua nota, ${ }^{7}$ e que demonstra que, em 2018, 54,6\% do corpo discente é formado por mulheres, sendo o curso um dos de maior predominância feminina. Essa realidade tem que ser considerada no sentido de reconhecer que as mulheres, historicamente sobrecarregadas pela cultura machista, neste momento de pandemia têm o sobretrabalho ampliado.

Vale registrar que o currículo dos cursos de Serviço Social prevê componentes que ultrapassam as paredes das salas de aula. Assim, a formação profissional se pauta na indissociabilidade entre ensino-pesquisa-extensão, necessitando dos espaços formativos de debates, seminários, cursos e também da organização autônoma do movimento estudantil. Sim, o movimento estudantil também forma! As assembleias discentes, os encontros de estudantes de Serviço Social, as atividades de paralisação e as greves de docentes e discentes também são formativas. Essas experiências, assim como os projetos de extensão com interação com comunidades, quilombolas, ribeirinhos, mulheres, periferias, povos indígenas, LGBTTI+, possibilitam aos estudantes experienciar, hoje, o que Gramsci (2001) identificou como o germe do amanhã.

No caso da contrarreforma administrativa, as incidências para a formação são ainda mais perversas e se articulam com a imposição do ensino remoto como forma hegemônica de formação para um mercado de trabalho flexibilizado e para serviços públicos desestruturados. A PEC no 32/2020 prevê, entre outras coisas, que militares da ativa possam ter

Disponível em: http://www.abepss.org.br/noticias/abepss-suspencao-calendario2020-pos-370. Acesso em: 10 out. 2020. 
cargos concomitantes nas áreas da educação e da saúde. Será isso uma nova tentativa de controle político dos cursos de graduação?

Ainda pode ter implicações, para a formação em Serviço Social nas instituições públicas de ensino, o fato de a PEC prever a possibilidade de contratação de cargos de confiança e assessoramento, a serem preenchidos por pessoas que não são do quadro do serviço público. Isso significa, para um governo que insiste em não respeitar sequer a consulta pública das instituições de ensino para a eleição de reitores, que as chefias imediatas podem ser preenchidas por cargos políticos de confiança do governo, inclusive militares.

Nesse sentido, compreendendo o chamado "novo normal" na educação como uma articulação entre ensino remoto emergencial, avanço do neoliberalismo, crise estrutural do capital, sucessivas contrarreformas, flexibilização do mundo do trabalho, destruição das políticas públicas e sociais, autoritarismo e imposição do pensamento único, a educação superior pública e de qualidade está sob ameaça. Como consequência, a defesa de um projeto emancipatório, nos termos de Marx (2009), previsto no código de ética do Serviço Social, dependerá do grau e da capacidade de resistência e de organização dos segmentos da classe trabalhadora, entre elas os assistentes sociais.

\section{Considerações finais}

É importante frisar que a contrarreforma da educação, que impacta a formação do Serviço Social, não virá de um único projeto proclamado pelo governo federal ou aprovado pelo Congresso Nacional. A contrarreforma já está em curso e está acontecendo de forma compartimentalizada, fragmentada, inclusive como estratégia para diminuir as resistências da comunidade acadêmica e das entidades organizadas da educação.

Não será necessário um projeto de venda das instituições de ensino superior pública, como querem fazer com outras estatais, a exemplo da Petrobras e dos Correios. A universidade, em sua aparência de pública, 
ainda é necessária para o projeto em curso do capital. As transformações no mundo do trabalho, que geram uma classe trabalhadora com direitos cada vez mais flexibilizados e submersos nas mediações tecnológicas, dispensam a qualificação profissional universitária, tal como é hoje no Brasil. Muitos cursos podem ser reduzidos a profissionalizantes, relegados às instituições privadas de ensino, pautados na mecânica preparação para o mercado de trabalho. As universidades públicas podem ser reduzidas a centros de formação, altamente especializados, para formar os "gerentes" do capital em um mundo desregulamentado. Assim, sua estruturação pode se dar pela parceria público-privada, pela venda de serviços e pelo domínio das organizações sociais e fundos patrimoniais.

Não devemos esperar que as portas das universidades públicas sejam fisicamente fechadas. A obstrução dar-se-á por outros caminhos. As portas, enquanto permanecem fisicamente abertas, se abrem cada vez mais para o mercado e se fecham para a perspectiva de uma sociedade humanizada e igualitária, em que a produção do conhecimento, de forma livre, seja condição para a emancipação da humanidade. 0 ensino superior no Brasil deve ser compreendido como resultado de um processo de amplas e longas disputas entre projetos distintos de sociedade e de formação. $O$ projeto que historicamente defendemos se encontra sob forte ataque do "novo normal", construído sob a égide do capital. Então, na perspectiva de construir uma educação emancipadora, como afirma Mézáros (2005, p. 27), “é necessário romper com a lógica do capital se quisermos contemplar a criação de uma alternativa educacional significativamente diferente".

\section{Referências}

ANTUNES, Ricardo. O privilégio da servidão: o novo proletariado de serviços na era digital. São Paulo: Boitempo, 2018.

ANTUNES, Ricardo. Coronavírus: o trabalho sobre fogo cruzado. São Paulo: Boitempo, 2020. BRASIL. Constituição Federal. Brasília, 1988. 
BRASIL. Decreto n 9.057, de 25 de maio de 2017. Regulamenta o art. 80 da Lei n 9.394, de 20 de dezembro de 1996, que estabelece as diretrizes e bases da educação nacional.

GRAMSCI, Antonio. Cadernos do cárcere. Rio de Janeiro: Civilização Brasileira, 2001.

IANNI, Octavio. Questão social. In: IANNI, Octavio. Pensamento social no Brasil. São Paulo: Ed. Edusc, 2004.

KONDER, Leandro. Marxismo e alienação: contribuições para um estudo do conceito marxista de alienação. São Paulo: Expressão Popular, 2009.

LIMA, K. R. de S. Contra-reforma na educação superior: de FHC a Lula. São Paulo: Xamã, 2007.

MARX, Karl.O capital: crítica da economia política. Rio de Janeiro: Civilização Brasileira, 2001. Livro 1, v. 1 e 2, e Livro 2.

MARX, Karl. Contribuição à crítica da economia política. São Paulo: Expressão Popular, 2007.

MARX, Karl. Para a questão judaica. São Paulo: Expressão Popular, 2009.

MÉSZÁROS, Istiván. A educação para além do capital. São Paulo: Boitempo, 2005.

\section{Sobre a autora}

Eblin FARAge - Professora da Escola de Serviço Social. Mestre e doutora em Serviço Social.

E-mail: farage.eblin@gmail.com 